The International Journal of Indian Psychology

ISSN 2348-5396 (e) | ISSN: 2349-3429 (p)

Volume 4, Issue 1, No. 75, DIP: 18.01.055/20160401

ISBN: 978-1-365-50727-4

http://www.ijip.in | October-December, 2016

\title{
Visual Imagery, Daydreaming and Affect among College Students
}

\author{
Arhana $\operatorname{Arya}^{1 *}$
}

\section{ABSTRACT}

The purpose of the study was to see the role of imagery in the development of emotion control, daydream, positive or negative effect. Total 90 subjects (45 males and 45 females) of age group 18-23 years were randomly selected. Males were selected from Amity College and females were taken from the residential students residing in Bansthali Vidyapith. On the basis of median split, the sample was categorized into two groups: 'high imagery' and 'low imagery'. Besides age, education level was controlled up to an extent so that the sample was homogeneous in these aspects. Care was taken to select only those participants who do not have a significantly unhealthy sleep routine and who were not using prescription medication. Informed consent was obtained prior to the study. The Positive and negative affect scale (PANAS), Emotional Control Questionnaire ECQ, Daydreaming Scale of the Imagine Process Inventory (IPI) and The Vividness of Visual Imagery Questionnaire (VVIQ) was employed as a questionnaire. To see the effect of imagery and gender on day dreaming, emotional control, positive Affect and negative Affect, two way ANOVA and descriptive statistics were employed and found significant effect of visual imagery and gender on day dreaming, and insignificant effects on emotional control, positive Affect and negative Affect at 0.05 level of significance.

Keywords: Visual Imagery, Gender, Day Dreaming, Emotional Control, Positive Affect And Negative Affect.

Visual imagery is information which passes through the brain as though something is being perceived, when nothing is actually happening. Someone may experience sight, smell, sound, and touch as a result of visual imagery when none of these stimuli are present. Also known as a mental image, visual imagery is a topic of great interest in psychology, and it has a number of potentially very interesting applications.

Two general classes of theories have been put forward to account for the details of the internal organization of visual mental images. Depictive theories embrace the view that visual mental images are distinct types of mental representations and function to depict visual objects and

\footnotetext{
${ }^{1}$ IBDP Psychology facilitator, The Cathedral Vidya School, Lonavala, Pune Maharashtra, India *Responding Author

(C) 2016 A Arya; licensee IJIP. This is an Open Access Research distributed under the terms of the Creative Commons Attribution License (http://creativecommons.org/licenses/by/2.0), which permits unrestricted use, distribution, and reproduction in any Medium, provided the original work is properly cited.
} 


\section{Visual Imagery, Daydreaming and Affect among College Students}

scenes (Kosslyn 1980; Shepard and Cooper 1982). Under this view, visual images make explicit shape and spatial relations by virtue of their internal structure: Distances among parts in the image correspond to distances among parts of the stimulus they represent. In contrast, nondepictive theories support the view that visual mental image representations are not different from the type of "propositional" representations used for general-purpose thought (Pylyshyn 1981). According to this view, the pictorial aspects of imagery available to introspection are epiphenomenal and play no role in information processing. During the "imagery debate" of the late 1970s and early 1980s, behavioral evidence was found both in favor and against both theories. As the debate unfolded, it became more and more clear that these questions about internal representations could not be answered conclusively, even with the novel empirical methods of cognitive psychology.

Daydreaming is a short-term detachment from one's immediate surroundings, during which a person's contact with reality is blurred and partially substituted by a visionary fantasy, especially one of happy, pleasant thoughts, hopes or ambitions, imagined as coming to pass, and experienced while awake. Both empirical evidence and everyday experience reveal we have a mind with a penchant for simulating alternative realities (Smallwood \& Schooler, 2006). Almost everyone reports engaging in some form of daydreaming on a daily basis (96\%; Singer \& McRaven, 1961), with estimates of how much of our day is devoted to daydreaming ranging from $30 \%$ to $50 \%$ (Killingsworth \& Gilbert, 2010; Klinger \& Cox, 1987). Yet there is no consensus on the role of daydreaming in emotional well-being. On the one hand, daydreaming provides a helpful means for escaping a banal existence. People commonly report deliberately launching into vivid daydreams to ease boredom at work, for example (Fisher, 1987; Singer, 1961). Daydreaming also alleviates emotional stress, conflict, and physical pain (Lang, 1995). In fact, individuals with a proclivity for daydreaming exhibit less physiological reactance to stressful events (Singer \& Antrobus, 1972), and asking people to daydream results in a less acute stress response for those anticipating an electric shock compared to those without such instructions (Rowe, 1963). In medical patients, guided daydreaming reduces the need for pain medication and shortens hospital visits (Antall \& Kresevic, 2004), as well as promotes greater overall well-being during recovery (Frick et al., 2008). Daydreaming has also been associated with other positive qualities that might promote happiness. Children with a disposition for internal musings exhibit more self-control and patience than children who have no such inclination (Singer, 1961), for example.

Social interactions and emotional involvements, to give an example, take-up a good share of our daily life and the social aspects of emotional expressions are being widely discussed (Blakermore, Winston \& Frith, 2004; Lieberman, 2007). They constitute an important aspect in human-robot interactions (Breazeal, 2003) and may even play a role in human phylogenies (Parr, Waller \& Fugate, 2005), having a high adaptive value (Rolls, 2005). The study of synthetic emotions (Picard, 2000) constitutes therefore a field of growing importance, dealing, 


\section{Visual Imagery, Daydreaming and Affect among College Students}

beside others, with the role of emotions in artificial intelligences in general (Minsky, 2007), social robots (Duffy, 2003; Fong, Nourbakhsh \& Dautenhahn, 2003), emotional expression in speech and language (Murray \& Arnott, 2008) and social synthetic computer characters (Tomlinson \& Blumberg, 2002).

Affect refers to the experience of feelings or emotions. Affect is a key part of the process of an organism's interaction with stimuli. The word also refers sometimes to affect display, which is "a facial, vocal, or gestural behaviour that serves as an indicator of affect" (APA 2006).

The affective domain represents one of the three divisions described in modern psychology: the cognitive, the cognitive, and the affective. Classically, these divisions have also been referred to as the "ABC of psychology", in that case using the terms "affect", "behaviour", and "cognition". In certain views, the cognitive may be considered as a part of the affective, or the affective as a part of the cognitive.

\section{PROCEDURE}

\section{Selection of Subjects}

Total 90 subjects (45 males and 45 females) of age group 18-23 years were randomly selected. Males were selected from Amity College and females were taken from the residential students residing in Bansthali Vidyapith. On the basis of median split, the sample was categorized into two groups: 'high imagery' and 'low imagery'. Besides age, education level was controlled up to an extent so that the sample was homogeneous in these respects. Care was taken to select only those participants who do not have a significantly unhealthy sleep routine and who were not using prescription medication. Informed consent was obtained prior to the study.

\section{Selection Of Variables}

Independent variables:

1- $\quad$ Visual Imagery

2- $\quad$ Gender

\section{Dependent Variables:}

1- $\quad$ Positive and negative affect

2- Emotional Control

3- Daydreaming

\section{Criterion Measures}

Following Questionnaires were taken as a criterion measures for selected variables:-

- Positive and negative affect scale (PANAS): Watson et. al. Comprises two mood scales, one measuring positive affect and the other measuring negative Affect. Each item is rated on a 5point scale. 


\section{Visual Imagery, Daydreaming and Affect among College Students}

- Emotional Control Questionnaire ECQ: Derek Roger \& Bahman Najarian. The ECQ2 is a 56-item scale that was constructed to measure emotional control. There are 4 factors that comprise the ECQ2: i) Rehearsal, ii) Emotional Inhibition, iii) Aggression Control, iv) Benign Control. The ECQ2 demonstrates very good internal consistency, with alphas of .86(Rehearsal), .77 (Emotional Inhibition), .79 (Benign Control), and .81 (Aggression Control). Test-retest reliability was assessed over a 7 week inter-test interval and was found to be substantial with a correlation of .80 (Rehearsal), .79 (Emotional Inhibition), .92 (Benign Control), and .73 (Aggression Control).

- $\quad$ Daydreaming Scale of the Imagine Process Inventory (IPI): G.J Huba, J.L. Singer, C.S. Aneshenesl, J.S. Antrobus. The IPI consists of two parts. Part 1 consists of 1-24 questions, which will be used in my study consisting of daydreaming. Internal consistency of $.80, .82$ and .83 .

- $\quad$ The Vividness of Visual Imagery Questionnaire (VVIQ): David Marks (Marks, 1973). It is a valid and reliable measure of vividness of mental imagery (LeBoutillier \& Marks, 2001; McKelvie, 1995). In a study in which 263 participants were assessed with the VVIQ, splithalf reliability was .88, and test retest reliability was .74 (McKelvie, 1995). It consists of four scenarios in which participants are asked to imagine and consider before their mind's eye, and then write down a number corresponding to their subjective vividness of the image.

\section{Statistical Procedure}

To find out the effect of imagery and gender on day dreaming, emotional control, positive Affect and negative Affect, two way ANOVA and descriptive statistics were employed. Statistical package for social science (SPSS) version 20 was used. For testing hypothesis the level of significance was set at 0.05 levels.

\section{RESULTS}

Table 1, Showing median of visual imagery scores

\begin{tabular}{|l|}
\hline Median \\
\hline 57.00 \\
\hline
\end{tabular}

Table 1 shows median value of visual imagery scores which was found to be 57.00. Using median split technique, the independent variable: visual imagery was divided into two groups (low and high). 
Visual Imagery, Daydreaming and Affect among College Students

Table 2, Showing Mean and SD of high visual imagery group and low visual imagery group in terms of dependent variables

\begin{tabular}{llcccc}
\hline S.No. & Dependent variables & \multicolumn{2}{c}{ Mean } & \multicolumn{2}{c}{ Std. } \\
& & $\begin{array}{c}\mathbf{M}_{\mathbf{1}} \\
\text { (low imagery) }\end{array}$ & $\begin{array}{c}\mathbf{M}_{\mathbf{2}} \\
\text { (high imagery) }\end{array}$ & $\begin{array}{c}\mathbf{S D}_{\mathbf{1}} \\
\text { (low imagery) }\end{array}$ & $\begin{array}{c}\text { (high } \\
\mathbf{S D}_{\mathbf{2}}\end{array}$ \\
\hline 1 & Emotion Control & 30.20 & 27.43 & 10.98 & 4.47 \\
2 & Day dreaming & 31.35 & 37.05 & 10.15 & 9.37 \\
3 & Positive Affect & 75.38 & 81.91 & 21.59 & 18.00 \\
4 & Negative Affect & 52.85 & 60.13 & 19.69 & 21.30 \\
\hline
\end{tabular}

Table 2 shows the Mean \& SD of low imagery group and high imagery group in terms of emotion control 30.20 (10.98) \& 27.43 (4.47), day dreaming 31.35 (10.15) \& 37.05 (9.73), positive affect 75.38 (21.59) \& 81.91 (18.00), negative affect 52.85 (19.69) \& 60.13 (21.30)

Table 3, Showing Mean and SD of males and females in terms of dependent variables

\begin{tabular}{llcccc}
\hline S. No. & Dependent variables & \multicolumn{2}{c}{ Mean } & \multicolumn{2}{c}{ Std. } \\
& & $\begin{array}{c}\mathbf{M}_{\mathbf{1}} \\
\text { (Male) }\end{array}$ & $\begin{array}{c}\mathbf{M}_{\mathbf{2}} \\
\text { (Female) }\end{array}$ & $\begin{array}{c}\mathbf{S D}_{\mathbf{1}} \\
\text { (Male) }\end{array}$ & $\begin{array}{c}\mathbf{S D}_{\mathbf{2}} \\
\text { (Female) }\end{array}$ \\
\hline 1 & Emotion Control & 27.57 & 29.91 & 7.66 & 8.85 \\
2 & Day dreaming & 32.11 & 36.47 & 11.05 & 8.69 \\
3 & Positive Affect & 80.65 & 76.97 & 19.40 & 20.54 \\
4 & Negative Affect & 57.14 & 56.16 & 19.71 & 21.94 \\
\hline
\end{tabular}

Table 3 shows the Mean \& SD of males and females in terms of emotion control 27.57 (7.66) \& 29.91 (8.85), day dreaming 32.11 (11.05) \& 36.47 (8.69), positive affect 80.65 (19.40) \& 76.97 (20.54), negative affect 57.14 (19.71) \& 56.16 (21.94)

Table 4, ANOVA showing effect of Visual Imagery and Gender on Daydreaming

\begin{tabular}{lllcccc}
\hline \hline S. No. & Variables & S.S & Df & Mean Square & F & Sig. \\
\hline 1 & Visual Imagery & 531.76 & 1 & 531.76 & $7.04^{*}$ & .010 \\
2 & Gender & 328.90 & 1 & 328.90 & $4.36^{*}$ & .041 \\
3 & Visual Imagery * Gender 1230.55 & 1 & 1230.55 & $16.30^{* *}$ & .000 \\
\hline
\end{tabular}

Table 4 shows the individual effect of visual imagery and gender on day dreaming separately. The $f$ value for visual imagery was found to be 7.04 which is statistically significant $(p<.05)$ the $f$ value for gender was found to be 4.36 which is statistically significant $(p<.05)$ the interaction effect of visual imagery and gender on day dreaming was also found to be significant as $f=16.30$ $(\mathrm{p}<.01)$ 
Visual Imagery, Daydreaming and Affect among College Students

Table 5, ANOVA showing effect of Visual Imagery and Gender on emotional control

\begin{tabular}{lllcccc}
\hline S. No. & Variables & S.S & Df & Mean Square & F & Sig. \\
\hline 1 & Visual Imagery & 152.54 & 1 & 152.54 & 2.24 & .13 \\
2 & Gender & 119.42 & 1 & 119.42 & 1.75 & .19 \\
3 & Visual Imagery * Gender 27.92 & 1 & 27.92 & .41 & .52 \\
\hline
\end{tabular}

Table 5 shows the individual effect of visual imagery and gender on emotional control separately. The $\mathrm{f}$ value for visual imagery was found to be 2.24 which is statistically not significant $\left(p^{>} .05\right)$ the $\mathrm{f}$ value for gender was found to be 1.75 which is statistically not significant $(p>.05)$ the interaction effect of visual imagery and gender on emotional control was also found insignificant as $\mathrm{f}=.41(\mathrm{p}>.01)$

Table 6, ANOVA showing effect of Visual Imagery and Gender on positive affect

\begin{tabular}{llccccc}
\hline S. No. & Variables & S.S & Df & Mean Square & F & Sig. \\
\hline 1 & Visual Imagery & 828.94 & 1 & 828.94 & 2.09 & .15 \\
2 & Gender & 284.64 & 1 & 284.6 & .71 & .40 \\
3 & Visual Imagery * Gender 219.93 & 1 & 219.93 & .55 & .45 \\
\hline
\end{tabular}

Table 6 shows the individual effects of visual imagery and gender on positive affect separately. The $f$ value for visual imagery was found to be 2.09 which is statistically not significant ( $p>.05)$. The $f$ value for gender was found to be .71 which is statistically not significant $(p>.05)$ the interaction effect of visual imagery and gender on positive affect was also found insignificant as $\mathrm{f}=.55(\mathrm{p}>.01)$

Table 7, ANOVA showing effect of Visual Imagery and Gender on negative affect

\begin{tabular}{lllcccc}
\hline S. No. & Variables & S.S & Df & Mean Square & F & Sig. \\
\hline 1 & Visual Imagery & 968.31 & 1 & 968.31 & 2.24 & .13 \\
2 & Gender & 33.19 & 1 & 33.19 & .07 & .78 \\
3 & Visual Imagery * Gender 153.27 & 1 & 153.27 & .35 & .55 \\
\hline
\end{tabular}

Table 7 shows the individual effects of visual imagery and gender on negative affect separately. The $\mathrm{f}$ value for visual imagery was found to be 2.24 which is statistically not significant ( $>>05$ ). The $\mathrm{f}$ value for gender was found to be .07 which is statistically not significant ( $>>05$ ). The interaction effect of visual imagery and gender on negative affect was also found insignificant as $\mathrm{f}=.35(\mathrm{p}>.01)$

\section{DISCUSSION AND CONCLUSION}

The present study focuses upon the influence of Imagery and Gender upon Daydreaming, emotion regulation and affect. For this purpose the sample was divided into high imagery group \& low imagery group by median split technique. 


\section{Visual Imagery, Daydreaming and Affect among College Students}

One of the objectives of the study was to examine the effect of imagery on daydreaming. For exploring this issue, mean scores of high and low imagery group were compared. Statistical analysis revealed that visual imagery significantly affected daydreaming. These findings support previous research (Antrobus, Antrobus, \& Singer, 1964; (MacCarely \& Hoffman, 1981).

In the present study, visual imagery was not found to be a significant factor in affecting emotion regulation. These findings support previous research (Hirsch \& Holmes, 2007; Foa \& Kozak, 1986).

Up to the knowledge of investigator very little research work has focused on the effect of high and low visual imagery on positive/negative Affect. However, visual imagery was found insignificant factor in influencing positive/negative Affect.

Another objective of the study was to examine the effect of gender on daydreaming. . For exploring this issue, mean scores of male and female group were compared. Statistical analysis revealed a significant difference between males and females with respect to daydreaming. Thus, in the present study, the effect of gender on daydreaming was significant these findings support previous research (Sutherland, 1971; Giambra, 1980)

In the present study, gender was found insignificant factor in influencing positive affect. This finding is consistent with previous research work done by Lavack \& Silvera (2005) in which the researchers found no significant differences between males and females on positive affect.

In the present study, gender was also found insignificant factor in influencing negative affect i.e., males and females did not differ significantly in terms of negative Affect. This finding contradicts previous research work done by Ardenti, Campari, Agazzi and Battista (1999) which related infertility with adaptive resources and studied the positive aspects of the women undergoing in vitro fertilization. The researchers concluded that males were more pessimistic and had more depressive thoughts leading to negative Affect. In another study conducted in Canada, researchers found that females had more negative Affect in comparison to males (Lavack \& Silvera, 2005). In this way we find a lot of inconsistency in findings pertaining to positive/negative affect with reference to gender. The probable reason behind these inconsistent findings may be due to the presence of some other moderating or uncontrolled variable. Also, the sample included in present study comprised of students in the age range of 18-23yrs- an age group in which there are no drastic emotional conflicts experienced in adolescence as well as not very significant pressure of responsibilities experienced at a more mature age. The aforesaid statement holds true for both males and females for the age range of participants taken in this study. May be due to this factor no significant effect of gender was found on positive/negative Affect. 


\section{Visual Imagery, Daydreaming and Affect among College Students}

In the present study, gender was not found to be a significant factor in affecting affect. The present research findings are supporting the previous research findings. Gross and John (2003) examined the impact of emotional regulation, they selected the two ethnic groups (Asian American and European American) and revisited each of the aspects of emotion regulation. They found no effect of sex or ethnicity for overall frequency of emotion regulation.

The interaction effect of imagery and gender on day dreaming was found to be significant. Although very little research has been done which focuses on the effect of the aforesaid variables on daydreaming. This could be because the individual effects of both visual imagery and gender on daydreaming were found to be significant so their interaction also yielded significant effect.

The interaction effect of imagery and gender on emotion regulation was not found to be significant. Although very little research has been done which focuses on the effect of the aforesaid variables on emotion control. This could be because the individual effects of both visual imagery and gender on emotion control were not found to be significant so their interaction also yielded insignificant effect.

The interaction effect of imagery and gender on positive and negative affect was found insignificant. Although very little research has been done which focuses on the effect of the aforesaid variables on positive and negative Affect. This could be because the individual effects of both visual imagery and gender on positive as well as negative affect were not found to be significant so their interaction also yielded insignificant effect.

Further investigations should be done which can provide a detailed description and analysis on the association of visual imagery, daydreaming and emotion. As currently, researchers are not unanimous in defining 'daydreaming' the investigator encountered several problems in its assessment. Also, research work on visual imagery either focuses on the effect of imagery intervention programs on athletes' performance in various sports or on certain specific groups and not on normal groups. More research work is needed to explore the dimensions of visual imagery as well as daydreaming

\section{Acknowledgments}

The author appreciates all those who participated in the study and helped to facilitate the research process.

\section{Conflict of Interests}

The author declared no conflict of interests.

\section{REFERENCES}

Aldao, A., \& Nolen-Hoeksema, S. (2010). Specificity of cognitive emotion regulation strategies: a transdiagnostic examination. Behaviour Research and Therapy, 48, 974-983. 


\section{Visual Imagery, Daydreaming and Affect among College Students}

Aldao, A.,Nolen-Hoeksema, S., \& Schweizer, S. (2010). Emotion-regulation stratgies across psychopathology: a meta-analytic review. Clinical Psychology Review, 30, 217-237

Borooah, V. K., 2010. Gender Differences in the Incidence of Depression and Anxiety: Econometric Evidence from the USA. J Happiness Stud, 11, 663-682.

Cole, P. M., Michel, M. K., \& Teti, L. O. (1994) The development of emotion regulation and dysregulation: A clinical perspective. (Vol. 59, pp. 73-100)

Davidson, R.J. (2000). Affective style, psychopathology, and resilience: Brain mechanisms and plasticity. American Psychologist, 55, 1196-1214.

Davidson, R.J., Jackson, D.C., \& Kalin, N.H. (2000). Emotion, plasticity, context, and regulation: Perspectives from affective neuroscience. Psychological Bulletin, 126, 890-909.

Fabes, R. A., Eisenberg, N., Jones, S., Smith, M., Guthrie, I., Poulin, R., Shepard, S., \& Friedman, J. (1999) Regulation, emotionality, and pre-schoolers' socially competent peer interactions, Child Development, 70, 432-442

Foxe, J.J. \& Snyder, A.C. (2011) The role of alpha-band brain oscillations as a sensory suppression mechanism during selective attention, Frontiers in Psychology, Art 154

Koole, S. L. (2009). The psychology of emotion regulation: An integrative review. (23 ed., Vol. 1, pp. 4-41). Psychology Press

Malloy, P., Rasmussen, S., Braden, W., \& Haier, R.J. (1989). Topographic evoked potential mapping in obsessive-compulsive disorder: Evidence of frontal lobe dysfunction. Psychiatry Research, 28, 63-71.

Ochsner, K.N., \& Gross, J.J. (2008) Cognitive emotion regulation: Insights from social cognitive and affective neuroscience. Currents Directions in Psychological Science, 17, 153-158.

Ochsner, K.N., Bunge, S.A., Gross, J.J., \& Gabrieli, J.D.E. (2002) "Rethinking feelings: An fMRI study of the cognitive regulation of emotion” Journal of Cognitive Neuroscience, 4, 1215-1229.

Ochsner, K.N., Ray, R.D., Robertson, E.R., Cooper, J.C., Chopra, S., Gabrieli, J.D.E., \& Gross, J.J. (2004). For better or for worse: Neural systems supporting the cognitive down- and upregulation of negative emotion. Neuroimage, 23, 483-499.

Pulkkinen, L. (1982). Self-control and continuity from childhood to late adolescence In P. B. Bakes \& O. Brim, Jr. (Eds.), Life-span development and behavior (Vol. 4, pp.63105) New York: Academic Press.

Thompson, R. A. (1994). Emotion regulation: a theme in search of definition. Monographs for the Society for Research in Child Development, 59, 25-52

Zeman, J., Cassano, M., Perry-Parrish, C., \& Stegall, S. (2006) “Emotion regulation in children and adolescents” Journal of Developmental and Behavioral Pediatrics, 27, 155-168.

Kosslyn SM (1980) Image and Mind. Harvard University Press, Cambridge, MA

Pylyshyn ZW (1981) The imagery debate: analogue media versus tacit knowledge. Psychol Rev 88:16-45

Shepard RN, Cooper LA (1982) Mental Images and their Transformations. MIT Press, Cambridge, MA 


\section{Visual Imagery, Daydreaming and Affect among College Students}

Antall, G. F., \& Kresevic, D. (2004) "The use of guided imagery to manage pain in an elderly orthopaedic population” Orthopaedic Nursing, 23(5), 335-341.

Fisher, C. D. (1987). Boredom: Construct, causes and consequences. Technical report ONR-9. Texas A\&M University

Rowe, P. (1963) "Individual differences in selection decisions” Journal of Applied Psychology, 47, 305-307.

Singer, J. L. (1961) "Imagination and waiting ability in young children” Journal of Personality, 29, 396-413.

Singer, J. L., \& Antrobus, J. S. (1972) "Daydreaming, imaginal processes, and personality: A normative study. In P. W. Sheehan (Ed.), The nature and function of imagery (pp. 175 202). New York, NY: Academic Press.

Lang, V. A. (1995) "Relative association, interactiveness, and the bizarre imagery effect" American Journal of Psychology, 108, 13-35

Klinger, E., \& Cox, W. M. (1987) Dimensions of thought flow in everyday life. Imagination, Cognition, and Personality, 7, 105-128

Blakermore, S.J., Winston, J. \& Frith, U. (2004) Social cognitive neuroscience: where are we heading? Trends in Cognitive Science, Vol. 5, pp. 216-222.

Breazeal, C. (2003) "Emotion and sociable humanoid robots" International Journal of HumanComputer Studies, Vol. 59, pp. 119-155

Duffy, B.R. (2003). Anthropomorphism and the social robot, Robotics and Autonomous Systems, Vol. 42, pp. 177-190

Minsky, M. (2007). The Emotion Machine: Commonsense Thinking, Artificial Intelligence, and the Future of the Human Mind. Simon \& Schuster.

Murray, I.R. \& Arnott, J.L. (2008). Applying an analysis of acted vocal emotions to improve the simulation of synthetic speech. Computer Speech \& Language, Vol. 22, pp. 107-129.

Lieberman, M.D. (2007). Social Cognitive Neuroscience: A Review of Core Processes. Annual Review of Psychology, Vol. 58, pp. 259-289.

Picard, R.W. (2000). Synthetic Emotion. IEEE Computer Graphics and Applications, Vol. 20, pp. 52-53.

Rolls, E.T. (2005) “Emotion Explained', Oxford University Press.

Parr, L.A., Waller, B.M. \& Fugate, J. (2005) "Emotional communication in primates: implications for neurobiology”. Current Opinion in Neurobiology, Vol. 15, pp. 716-720.

Tomlinson, B. \& Blumberg, B. (2002) "Social synthetic characters", Computer Graphics, Vol. 26, pp. 5-7.

How to cite this article: A Arya (2016), Visual Imagery, Daydreaming and Affect among College Students, International Journal of Indian Psychology, Volume 3, Issue 4, No. 75, ISSN:2348-5396 (e), ISSN:2349-3429 (p), DIP:18.01.055/20160304, ISBN:978-1-365-50727-4 